\title{
FEDERALISMO E CENTRALIZAÇÃO NO BRASIL: CONTRASTES NA CONSTRUÇÃO DA FEDERAÇÃO BRASILEIRA
}

\section{FEDERALISM AND CENTRALIZATION IN BRAZIL: CONTRASTS IN THE CONSTRUCTION OF THE BRAZILIAN FEDERATION}

\author{
Leonam Baesso da Silva Liziero ${ }^{1}$ \\ Fabrício Carvalho
}

\section{Resumo}

Formalmente, a federação brasileira surge com o Decreto $\mathrm{n}$ ㄴ1, de 15 de novembro de 1889, forma que foi posteriormente ratificada Constituição Republicana de 1891. Com a adoção explícita do modelo federativo, todavia, não desaparecem as forças centralizadoras, iniciandose um período de alternância entre movimentos de descentralização e movimentos de forte centralização. O modelo federativo de Estado pressupõe um nível razoável de descentralização, mas que nem sempre encontra correspondência nos Estados federativos reais, que se desenham a partir de uma dinâmica complexa e que envolve tanto fatores internos quanto externos. Tal dinâmica tem levado modelos concretos clássicos - como os Estados Unidos da América e a República Federal da Alemanha - a adotar medidas tendentes à centralização. Embora a Constituição de 1988 tenha rompido com a centralização excessiva do regime constitucional anterior e tenha logrado implementar um modelo com viés cooperativo, é visível a preeminência da União sobre os demais entes federativos.

Palavras-chave: Federalismo brasileiro; Centralização; Estado federal; Federalismo norteamericano; Federalismo alemão.

\begin{abstract}
Formally, the Brazilian federation appears with Decree no1, of November 15, 1889, form that was later ratified Republican Constitution of 1891. With the explicit adoption of the federative model, however, the centralizing forces do not disappear, beginning a period of alternation between movements of decentralization and movements of strong centralization. The federative state model presupposes a reasonable level of decentralization, but does not always find correspondence in the real federative states, which are designed from a complex dynamics that involves both internal and external factors. Such dynamics have led to classic concrete models - such as the United States of America and the Federal Republic of Germany - to adopt measures for centralization. Although the 1988 Constitution broke with the excessive centralization of the previous constitutional regime and succeeded in implementing a model with a cooperative bias, the Union's pre-eminence over other federal entities is visibl.
\end{abstract}

\footnotetext{
${ }^{1}$ Pós-Doutorando em Direito pela Universidade Federal do Rio de Janeiro - FND/UFRJ. Pesquisador do Laboratório de Estudos Teóricos e Analíticos sobre o Comportamento das Instituições Letaci/PPGD/FND/UFRJ. E-mail: leonamliziero@gmail.com

2 Mestre em Direitos Fundamentais e Democracia pelo Centro Universitário Autonomo do Brasil UniBrasil. E-mail: fabriciocarvalho.fc@hotmail.com
} 
Keywords: Brazilian federalism; Centralization; Federal State; American Federalism; German Federalism.

\section{INTRODUÇÃO}

A forma de Estado federal foi a vitoriosa na Constituinte de 1988, no projeto do novo Estado brasileiro após os anos sob a égide da autoritária Constituição de 1967. A tradição do federalismo na república brasileira foi mantida, ainda que com peculiaridades típicas da organização política brasileira.

Considerando que o sistema de freios e contrapesos é essencial para a estabilização e manutenção de um conceito material de Estado de Direito em contraste com o uso retórico da nomenclatura, o federalismo transcreve-se na tensão constante de poder entre os poderes das unidades federativas e o poder da federação.

Nesse sentido, a forma federativa realiza uma completude com a separação do poder soberano em Poderes funcionais baseados na divisão do trabalho, que em conjunto limitam o poder de atuação do Estado, seja na criação, seja na aplicação de normas para a consecução de seus fins. O controle do poder político e sua submissão ao direito, mas especificamente à Constituição da República, é verificada também na vigilância recíproca entre poder central e poderes regionais, ainda que no Brasil haja uma tradição constitucional de se conferir à União uma concentração maior de poder do que em outros Estados de forma federal, como os Estados Unidos, Alemanha e Suíça.

Apesar da tradição federalista no Brasil, a Constituição da República de 1988 apresenta um federalismo fraco, que ainda projeta a nação em um passado de autoritarismo e de construção social imposta pelo poder central. Há no federalismo brasileiro algumas características de unitarismo, que ainda guardam as influências de Constituições de cunho autoritário anteriores como a de 1937 e a de 1967, além da Emenda Constitucional no1 de 1969.

Assim, será demonstrado que o sistema político constitucional brasileiro é caracterizado por um federalismo fraco, mas que não descaracteriza o projeto constitucional de 1988 como um Estado Democrático de Direito, organizado sob a forma de um Estado federal. Este federalismo fraco será demonstrado sobretudo dentro de algumas normas constitucionais, que basicamente cuidam de três aspectos: o excesso de competências executivas e legislativas da União em detrimento dos Estados, o Distrito Federal e os Municípios; a intervenção federal em 
caso de afronta aos chamados princípios constitucionais sensíveis; e o reconhecimento do Município como unidade federativa, perfazendo uma descentralização vertical do poder em três níveis.

\section{A FORMA FEDERATIVA DO ESTADO}

No estudo das formas de Estado, o federalismo se caracteriza por apresentar uma forma intermediária entre o unitarismo e a confederação. O federalismo se caracteriza por ser uma organização política que reúne algumas características dos dois modelos, mas que também possui certa particularidade, apesar de se manifestar de forma diferente dependendo do país.

O princípio federal reza que deve haver a existência de mais de um Estado que estejam associados por algum motivo e que conservem parcelas de sua soberania em seu âmbito interno, ainda que nas relações exteriores a criação de um espaço próprio para isso se faça necessário. Essas parcelas de soberania são comumente denominadas de autonomia, pois cada Estado pertencente à uma federação tem a competência de se administrar, de fazer leis e ter um orçamento próprio, ainda que lhe falte o poder político pertencente à soberania, tanto no conjunto interno, quanto em relação a outros Estados.

Não se pode falar em "reunião de Estados soberanos", pois a partir do momento em que a Federação é constituída, perde-se a soberania de cada qual e se transfere para o ente criado a partir da união desses Estados. O ente em si é denominado por "União" ou "Poder Federal" e geralmente reúne funções relacionadas à manutenção da unidade entre os Estados, de conflito entre eles e de proteção contra invasões estrangeiras.

A proteção do Estado era a justificativa de Locke ao elaborar uma teoria do governo com o Poder Federativo. Tal como Hobbes faz, Locke pensa a sociedade internacional como um Estado de natureza em que toda a comunidade conta como um só ser em meio a tantos outros. Nesse caso, seria necessário um terceiro poder além do Legislativo - para a elaboração das leis - e do Executivo - para a perpétua execução dessas leis - que fosse o responsável pela salvaguarda do Estado. Conforme disserta Locke (1979, p.92): “Aí se contém, portanto, o poder de guerra e de paz, de ligas e alianças, e todas as transações com todas as pessoas e comunidades estranhas à sociedade, podendo chamar 'federativa', se assim quiserem".

Na tradição da teoria política posterior, o federalismo passa a se constituir como uma forma de organização do Estado. Na mais clássica obra sobre o assunto, "O Federalista" de Madison, Hamilton e Jay, o federalismo é debatido como a única saída para a manutenção e 
consolidação da independência das colônias e de ao menos manter a liberdade de cada Estado não se subordinar totalmente a um poder maior, de forma a proteger a autodeterminação de cada Estado e os direitos de seus grandes proprietários de terras. Nesse caso, o poder federal seria estruturado sobretudo para garantir os direitos dos Estados e evitar a sobrepujança de um sobre outro.

É necessário, para se pensar em um Estado federal, traçar alguns pontos que caracterizam essa forma de organização política. Nesta união permanente de Estados, as relações entre eles têm seus fundamentos essenciais delimitados por uma Constituição escrita, que se constitui em contrato de aliança perene. Por meio desse pacto, os Estados membros abrem mão da soberania - em favor do Estado central - para gozar das vantagens de pertencer a uma comunidade política maior. A organização constitucional da federação, portanto, estrutura-se sobre a ideia de equilíbrio entre o atendimento dos interesses relativos à unidade nacional e a realização daqueles interesses vinculados à autonomia regional, de modo a promover uma estabilidade duradoura e proveitosa para todos os entes federados (LOEWENSTEIN, 1979, p.356).

Vale observar que o conceito de federação, embora fortemente ligado ao conceito de federalismo, com ele não se confunde. A distinção entre estas categorias, ainda que tomada brevemente, pode conferir maior clareza à exposição da matéria.

Enquanto o federalismo se define como uma categoria normativa - referindo-se à ideia de um governo múltiplo, combinando tanto elementos de governo comum como de governo regional -, a federação representa uma categoria descritiva, pois se apresenta como espécie do gênero sistema político federal, gênero este que engloba uma extensa categoria de sistemas políticos em que há dois ou mais níveis de governo e que se reúnem "elementos de governo compartilhado nas instituições comuns e autogoverno regional nas unidades constituintes". As quase-federações, as federações e as confederações compõem o grupo de formas não unitárias do gênero sistema político federal. As federações são, assim, uma espécie particular deste gênero, na qual não há relação de subordinação entre o governo central e os governos das unidades federadas, haja vista que as competências de cada ente federativo são definidas constitucionalmente (WATTS, 2006, p.105). Se o federalismo se estrutura como categoria normativa, a federação, por sua vez, caracteriza-se como um dado da realidade concreta, ou seja, uma forma de organização política efetivamente adotada. 
Daniel Elazar (1987, p.40), analisando a experiência federal estadunidense, observa que o federalismo moderno se fundamenta na ligação entre os estados federados que, unidos, formam um estado maior e soberano.

Ao tratar do problema da soberania, o federalismo norte-americano acabou por apresentar uma alternativa moderna e mais democrática relativamente à organização da política, desenvolvendo a ideia de que a soberania é uma qualidade relativa ao povo. Ronald L. Watts (2006, p.98, tradução nossa) afirma que as federações são "organizações políticas compostas que combinam fortes unidades constituintes e um governo central igualmente forte, cada um em posse de poderes delegados pela cidadania através da Constituição".

Isso significa que as diversas esferas de governo - federal, estadual e local - exercem tão somente poderes delegados. Os diferentes governos existentes no interior de um Estado, desta forma, relacionam-se entre si como iguais, desenvolvendo suas respectivas tarefas em estrita observância aos poderes delegados a cada um deles (ELAZAR, 1987, p.41).

Os Estados federados atuais caracterizam-se, antes de tudo, como Estados democráticos, que em alguns casos nasceram já com essa característica, enquanto que, em outros casos - a maioria -, nasceram como Estados constitucionais em vias de democratização (VALDÉS, 2012, p.23). Considerando que o verdadeiro federalismo, em todas as suas espécies, tem por interesse principal a liberdade (ELAZAR, 1987, p.91), ele só poderá desenvolver-se, genuinamente, em um contexto democrático.

Nesse sentido, Watts (2006, p. 107, tradução nossa) observa que uma das características mais importantes dos processos de federalização é

Uma forte predisposição à democracia já que tais processos presumem um consentimento voluntário dos cidadãos das unidades constituintes, a não centralização como um princípio expressado através de múltiplos centros de decisão política, a abertura da negociação política como nota distintiva da forma em que se adotam as decisões, o funcionamento de um sistema de controles para evitar uma concentração de poder político e um respeito ao constitucionalismo desde o momento em cada decisão governamental deriva sua autoridade da Constituição.

Não obstante os diversos aspectos particulares que marcam cada uma das federações, Watts (2006, p.106) observa que estas apresentam características estruturais comuns, sendo elas: i) a existência de duas ordens de governo que atuam diretamente sobre seus cidadãos; ii) uma divisão constitucional formal dos poderes legislativo e executivo e a distribuição de fontes de financiamento entre as diferentes esferas de governo, o que acaba por garantir algumas áreas de plena autonomia para cada instância de governo; iii) a previsão de um espaço de representação das regiões (enquanto unidades federativas) dentro das instituições políticas 
federais; iv) uma Constituição escrita dotada de supremacia e que requer, para sua modificação, o consentimento de uma parte significativa das unidades constituintes da federação; v) a existência de um árbitro (que pode ser um tribunal ou por meio de organização de referendos) para o julgamento dos litígios federativos; vi) a existência de procedimentos e instituições que tem por objetivo facilitar a colaboração intergovernamental em matérias de competências compartilhadas ou superposta.

Elazar, em Contrasting Unitary and Federal Systems, conforme a observação de modelos políticos desenvolvidos na modernidade, propõe a comparação entre três modelos de organização do Estado, correspondentes a expressões de um tipo ideal, ainda que compartilhem características. Os modelos propostos por Elazar (1997, p.238) são: (i) piramidal, (ii) centro-periferia e (iii) matricial. A grande diferença entre estes modelos é a posição dos mecanismos governamentais, apesar de terem outras diferenças marcantes.

Os Estados federais se organizariam conforme o modelo matricial, o que representa uma alteração paradigmática em contraste com a concentração política dos outros dois modelos. O modelo matricial "reflete uma política composta de arenas com arenas mantidas juntas pelo enquadramento de instituições comuns e um compartilhamento de informações em rede" (ELAZAR, 1997, p,239). A estrutura deste modelo é representada por células em um mesmo quadro, como uma matriz matemática na qual os diversos núcleos de poder se comunicam. Neste modelo, a Constituição é predominante (ELAZAR, 1997, p.241).

Um traço marcante do Estado federal e que, a despeito de sua importância, por vezes não se menciona, é a existência de uma cultura federal, que atua como uma espécie de base sobre a qual se assenta a arquitetura federal, por sua vez composta pela Constituição e pelas diversas instituições federais. Essa cultura federal funciona ainda como um freio às tendências separatistas, ao mesmo tempo em que se caracteriza como um instrumento de distribuição de poder, de modo a conter movimentos centralizadores (VALDÉS, 2012, p.28-29).

Valdés (2012, p.29-30, tradução nossa) observa que essa cultura federal diz respeito à existência de uma "mentalidade federal", ou seja, uma maioria de cidadãos genuinamente convencidos de que "não apenas é possível, mas também desejável, conjugar autogoverno e governo compartilhado, o que exige por seu turno uma disposição abrangente para a negociação, para o pacto e para a compreensão das virtudes da diversidade e da colaboração".

A adoção do modelo federal por diversos países ocorrida nos séculos XIX e XX - o que Elazar (2011, p.439) chama de revolução federalista - repousa sobre três fenômenos essenciais da vida política desenvolvida na modernidade, quais sejam: i) o surgimento do Estado-nação 
moderno, com territórios relativamente extensos e populações volumosas, o que levantou problemas no tocante à distribuição interna de competências para estas organizações políticas expandidas; ii) a ruptura, com a modernidade, com o modelo pré-moderno de comunidade e suas linhas de autoridade essencialmente estruturadas em relações sociais fixas. Esta ruptura se fez acompanhar da necessidade de criação de novas formas de vínculos locais e de autogoverno; iii) a ruptura com os velhos princípios aristocráticos para se abrir espaço a um novo compromisso em favor da igualdade, ao mesmo tempo que se reivindicava a fundação de uma ordem política e social de caráter democrático.

\section{CONTRASTES ENTRE O FEDERALISMO BRASILEIRO, O NORTE-AMERICANO E O ALEMÃO}

Pode-se realizar um estudo comparado entre as diversas formas de federalismo desenvolvido a partir de dois icônicos modelos, o norte-americano e o alemão. Os dois foram construídos sob bases teóricas bem diferentes - o que será brevemente explorado -, mas chegaram a resultados formais semelhantes, o que permite identificá-los como Estados federais.

Apesar de existirem diversos Estados federais no mundo contemporâneo - cerca de vinte e cinco -, é possível verificar algumas matrizes provenientes do federalismo alemão (genericamente falando) ou do federalismo norte-americano. A construção do Estado federal brasileiro - não necessariamente do federalismo brasileiro -, por exemplo, teve suas bases na Federação estadunidense.

Então para verificar o contraste entre estas duas matrizes do federalismo moderno, e consequentemente, dos Estados federais, é necessário fazer algumas considerações sobre tantos os fundamentos teóricos quantos sobre as condições que possibilitaram o surgimento de cada um deles.

Apesar do federalismo norte-americano ser hodiernamente considerado o primeiro movimento político moderno desta natureza a ter sido desenvolvido e os Estados Unidos o primeiro Estado federal surgido com tal configuração na história moderna, as raízes teóricas do federalismo alemão são mais antigas, que remontam a Johannes Althusius (1563-1638).

Já no início do século XVII, Althusius (1995, p.67, tradução nossa) escrevia:

Os membros de um reino, ou dessa associação simbiótica universal, não são, eu afirmo, homens, famílias ou grupos colegiados, como em uma 
associação privada ou em uma associação pública específica. Os membros de um reino são, em verdade, as muitas cidades, províncias e regiões, que concordam entre si em formar um corpo único constituído pela união mútua e pela comunicação.

Thomas Hueglin e Bernard Voyenne consideram Johannes Althusius como um homem situado entre a idade média e a idade moderna, e que descobriu elementos centrais da teoria federalista, como i) a concepção de Estado enquanto aglutinação de províncias e regiões, ii) a concepção da soberania partilhada entre os poderes constituintes, rejeitando-se a ideia de soberania absoluta, e iii) a compreensão de sociedade global enquanto unidade de relações recíprocas entre grupos (BENOIST, 1999, p.54).

A principal preocupação de Althusius centrava-se na constituição do federalismo enquanto um processo sócio-político de convivência pacífica e harmônica, procedendo, por essa razão, a uma abordagem do federalismo enquanto filosofia social (HUEGLIN, 1994, p.65).

Recentes pesquisas, como observa Burgess (2006, p.190), demonstram que o pensamento político federal de Althusius - assim como o de Heinrich Bullinger - influenciaram fortemente a construção tanto da tradição federal da Europa Continental como da tradição norte-americana.

Os primeiros princípios políticos proclamados de forma sistemática nos Estados Unidos da América foram prolongamentos e adaptações da teologia federal dos puritanos, "que viam a sociedade como uma extensão das alianças bíblicas básicas entre Deus e seu povo". A ideia pactista, nos Estados Unidos da América, embora tenha sido difundida de forma mais eloquente pelos puritanos, também foi propagada naquele país por outros grupos que haviam sido educados em congregações estruturadas sobre a ideia de pacto (ELAZAR, 2011, p. 93-94).

Esta tradição espalhou-se tanto que, no ano de 1776, mais da metade das congregações eclesiásticas existentes na nova nação tinham por base princípios pactistas. Em um primeiro momento, os pactos básicos da cidade e da congregação promoveram a união de indivíduos e famílias. Simultaneamente, desenvolveram-se redes de associações voluntárias em diversas áreas - no campo social, comercial, eclesiástico e civil - e de cunho não governamental, demonstrando que a própria sociedade norte-americana se assentava sobre o princípio do pacto livre. No início, as redes comunitárias estruturaram-se como colônias, passando, mais tarde, para a condição de Estados, até que, por fim, a rede de Estados formou a União federal.

Vale observar que, além da influência da ideia pactista de origem eclesiástica precisamente apontada por Elazar, diversos outros fatores contribuíram para a formação da ideia federal nos Estados Unidos da América. Esta a razão pela qual Burgess (2006, p. 51 e 
p.177) afirma que as origens da ideia federal naquele país são tão complexas quanto profundas. Estendendo-se desde o século XVII, elas abrangem o pensamento filosófico da Europa Continental, as políticas imperiais britânicas e a prática colonial norte-americana, bem como a duradoura influência da obra clássica O Federalista, de Hamilton, Madison e Jay.

Para Elazar (2011, p.95), esta é a razão pela qual o federalismo representa para os norte-americanos muito mais que um acordo governamental estabelecido entre os estados membros. O federalismo, nos Estados Unidos da América, constitui-se como a base de um verdadeiro estilo de vida política.

Com a Constituição norte-americana de 1787 - como já se observou - nasce o primeiro modelo federal da história, sendo marcado, essencialmente, por quatro traços específicos. 0 primeiro, presente em toda e qualquer ordem de cunho federal, refere-se à divisão de competências entre a União e os Estados membros. Ao lado da repartição de competências como segundo traço - o modelo federal nascente instituirá mecanismos de participação dos Estados membros nas instituições federais de governo, sendo que a mais importante será a participação destes nas eleições dos integrantes do Senado, permitindo, assim, que a formação da vontade do governo federal contasse com a colaboração dos Estados. O terceiro atributo consiste no fato de que, ao lado do Congresso americano e do presidente da União, a Constituição de 1787 previa um poder judiciário federal que tinha como órgão máximo um Tribunal Supremo, que, entre outras funções, foi instituído para conferir uniformidade às decisões judiciais. O quarto traço diz respeito às normas constitucionais que dificultam a modificação do seu próprio texto ou que limitam as modificações das fronteiras dos Estados sem a participação destes no processo de tomada de decisão (VALDÉS, 2012, p.51-55).

O federalismo norte-americano nasce como um modelo dual - ou seja, uma separação estanque das atribuições da União e dos Estados -, sendo este modelo superado posteriormente, com a chamada revolução constitucional de 1937 e com a adoção da política do New Deal, pelo modelo denominado federalismo cooperativo. Os problemas econômicos e sociais gerados pela crise de 1929 acabaram por convencer os Estados membros americanos que eles não eram aptos para resolver, sem o auxílio do governo federal, tais problemas. No final, o New Deal acabou sendo um impulso à centralização (VALDÉS, 2012, p.252).

Esta tendência centralizadora tem se manifestado sobretudo pela privação dos chamados "poderes reservados", garantidos pela Emenda n.ำ 10 da Constituição norteamericana. Em sua formulação pura, o modelo de federalismo centralizado tem como premissas fundamentais: o compartilhamento das funções e responsabilidades; a dependência 
dos poderes regionais e locais em relação às decisões tomadas no âmbito do poder central, decisões estas que têm efeitos sobre todo o país; a debilitação das instituições políticas difusas, como os governos dos Estados, suas respectivas assembleias legislativas e os governos locais, fazendo com sua influência nas políticas determinantes seja irrelevante; a reunião das funções antes desempenhadas pelas instituições políticas difusas em um sistema hierárquico centralizado (LÓPEZ-ARANGUREN, 1999, p.20).

No entanto, nos Estados Unidos da América, a chamada "devolution revolution" - uma série de medidas implementadas desde o governo do presidente Ronald Reagan, entre as quais a aprovação do Unfunded Mandate Reform Act of 1995 (UMRA) - vem buscando restabelecer o equilíbrio entre os poderes do governo federal e dos governos estaduais.

O modelo federal alemão, com a Lei Fundamental de Bonn, também caminhou em direção à centralização. Antonio Arroyo Gil (2006, p.32, tradução nossa) afirma que "a Lei Fundamental, em suas entranhas, acolheu um modelo de Estado federal com importantes traços centralizadores, sendo que os elementos unitários têm uma presença tão importante na Constituição alemã quanto os elementos federativos".

O sistema federal alemão, desde o seu início, mostrou-se bastante eficiente. Apesar das diversas críticas, "o sistema federal alemão funcionou de forma efetiva mesmo durante períodos em que maiorias diferentes controlavam a câmara baixa (Bundestag) e a segunda câmara (Bundesrat)" (BURGESS, 2006, p.199, tradução nossa).

A Federação alemã, segundo Watts (2006, p.124), "deve seu bom funcionamento à precoce experiência do Império Alemão (1871-1918), à República de Weimar (1919-1934) e ao fracasso da centralização totalitária do Terceiro Reich (1934-1945)". Após a queda do Terceiro Reich, as noções de federalismo e federação passaram a compor o conjunto das principais características da Alemanha ocidental do segundo pós-guerra, sendo institucionalizadas na Lei de Bonn, em 1949. A nova federação (Bundesstaat) estruturou-se, em especial, a partir de três fatores: 1) a distribuição de tarefas foi desenhada junto com novas competências; 2) o Bundesrat (segunda câmara) representou os governos dos Länder, o que acabou por conferir a estes uma posição robusta no processo federal de tomada de decisão; 3) o Bundesstaat (Estado Federal) adotou uma forte cooperação (GIL, 2006, p.12) tanto no plano horizontal como no plano vertical (BURGESS,2006, p. 199).

Não há dúvida que o regime federal estabelecido pela Lei Fundamental de Bonn acabou por conceder ao Bund destacada vantagem no campo das competências legislativas, estabelecendo um complexo processo de centralização. Afirma-se que se estabeleceu um 
processo complexo de centralização porque a perda significativa do poder legislativo singular dos Länder foi, de certa forma, compensada pelo incremento da participação coletiva destes na formação da vontade legislativa federal, por meio do aumento do número de leis que exigem o consentimento do Bundesrat - órgão parlamentar federal de representação governamental dos Länder - para sua aprovação (ROVIRA, 1986, p. 360-361).

O federalismo alemão, desde seu início, tem sido marcado pela inter-relação e pela colaboração entre as esferas federal e estatal. O acento sobre a dimensão cooperativa é uma das características mais destacadas da tradição federal alemã, estando presente desde a primeira formação federal daquele país - o II Reich (ROVIRA, 1986, p.352).

A cooperação, todavia, produziu um deslocamento da capacidade de decisão em direção das instâncias executivo-governamentais do Bund e dos Länder, motivo pela qual alguns autores chegam a falar em uma "desparlamentarização do sistema político (Kisker), e do avanço tendencial em direção a um Estado federal dos Governos (Böckenforde)" (ROVIRA, 1986, p.549550).

Este quadro de governamentalização da cooperação, entre outros efeitos, acabou por colocar em primeiro plano todas as questões ligadas ao financiamento do Estado federal, devido a dois fatos: o primeiro, o de que todos os programas e sistemas de cooperação dependem de recursos financeiros; ii) o segundo, o de que são os governos - federal e estaduais - os que "controlam a elaboração, aplicação e o controle dos orçamentos públicos" (VALDÉS, 2012, p.292, tradução nossa).

Visando superar as dificuldades decorrentes, entre outros fatores, do sofisticado processo de cooperação federativa adotado, a Alemanha iniciou uma reforma constitucional do seu modelo de federalismo, dentre as quais se destacam aquelas levadas a efeito no ano de 2006. Estas reformas foram implementadas com o objetivo de desembaraçar a atuação e a aprovação das decisões tomadas em nível federal, reduzindo-se, para isso, o número de leis federais que exigem - para sua aprovação - a anuência do Bundesrat. Fortemente vinculado a este primeiro objetivo, a reforma constitucional visou aclarar as responsabilidades políticas das partes que compõem o processo legislativo. O terceiro objetivo da reforma foi o de melhorar a eficiência estatal no cumprimento de suas respectivas tarefas públicas (GIL, 2009, p.31-33).

No Brasil, a forma federativa foi adotada formalmente com a edição do Decreto $\mathrm{n}$ ㅇ 1 , de 15 de novembro de 1889, o que a Constituição de 1891 posteriormente ratificou. Embora a experiência estadunidense tenha sido a principal influência para a federação brasileira nascente, não se pode afirmar que esta foi mera cópia do modelo federal norte-americano 
(SOUZA, 2005, p.105). A diferença entre os modelos revela-se não apenas na forma assumida pelo federalismo brasileiro, mas também na própria origem deste. No Brasil não existiam unidades territoriais autônomas - ao contrário dos Estados Unidos da América - no momento anterior à formação da União, haja vista que as Províncias representavam a forma de divisão territorial do Império do Brasil (HORTA, 2003, p.322).

A repartição de competências, o "coração" de qualquer sistema federativo, no Brasil sofreu influências diretas, em momentos diferentes, tanto da Constituição norte-americana, quanto do federalismo alemão. O momento de maior influência norte-americana se mostra justamente na emergência do Estado federal brasileiro, imposto pelo Decreto nำ1, de 15 de novembro de 1889 e pela Constituição de 1891. Apesar das diferenças pretéritas à forma federativa em Estados Unidos e Brasil, a Constituição de 1891 trouxe distribuição de competências semelhante à dos norte-americanos: poderes enumerados para a União e poderes residuais para os Estados.

Essa primeira Constituição da República trazia o ajustamento entre a União e os Estados federados nos quinze primeiros artigos. Os arts. 16 a 62 tratavam de organizar a União, com destaque para suas competências não tributárias que constavam no art. 34, dentro da enumeração dos poderes do Congresso Nacional. Por sua vez, os Estados federados eram regulamentados pelos arts. 63 a 66. Especialmente, o art.63 determinava que os Estados eram regidos por suas Constituições e suas leis, desde que respeitados os princípios constitucionais da União.

Em outro momento da história constitucional brasileira se observa alguma influência do federalismo alemão, sobretudo na repartição de competências da Constituição de 1988. De uma repartição anterior, da Constituição de 1967, que solapava a autonomia dos Estados, deixando-as residuais (art.13, §1으), com poderes enumerados da União (art. 8으) e dos Municípios (art. 16, II), a técnica de repartição de competências na Constituinte de 1987/1988 é semelhante à adotada pela Lei Fundamental de Bonn, de 1949.

O grande expoente deste complexo sistema de repartição de competências, com competências privativas, exclusivas, comuns e concorrentes, foi Raul Machado Horta, catedrático professor da Faculdade de Direito da UFMG. Desde os anos 1950, Horta publicou diversos artigos de profunda relevância para o pensamento federativo brasileiro. Não demais, foi o escolhido para relatar o Comitê de Federação e Organização Tributária da Comissão Afonso Arinos, em 1986. 
Horta, em vários escritos, defendia a técnica de repartição de competências da Lei Fundamental de Bonn com a mais moderna. Esta sua posição fica bem evidente em um artigo publicado em 1985, Organização Constitucional do Federalismo, publicado na Revista de Informação Legislativa. Segundo Horta (1985, p.13),

A repartição de competências do novo federalismo alemão compreende dois seguimentos fundamentais: o da legislação exclusiva da Federação e o da legislação concorrente ou comum, uma concorrência mista, a ser explorada pela Federação e pelos Estados, conforme regras estabelecidas na Lei Fundamental.

Nesse mesmo artigo, Horta (1985, p. 14), menciona a respeito sobre a técnica de repartição de competências que a nova Constituição (que seria promulgada em 1988) deveria adotar, baseada nesta do federalismo alemão:

É nesse federalismo de equilíbrio que deverá inspirar-se o constituinte federal brasileiro, para que possa levar a bom termo a restauração do federalismo brasileiro, de forma que o indispensável exercício dos poderes federais não venha inibir o florescimento dos poderes estaduais.

E continua, ao observar que a nova ordem constitucional brasileira deveria tender à descentralização, de modo a estabelecer uma categoria de competências comuns:

O deslocamento de matérias da competência exclusiva da União para o da legislação comum, a ser objeto de dupla atividade legislativa, a da União no domínio da legislação de normas gerais e a do Estado na complementação da legislação federal, representaria um reforço quantitativo e qualitativo da competência estadual para legislar (HORTA, 1985, p.15).

Sua relatoria no Comitê de Federação e Organização Tributária na Comissão Afonso Arinos gerou a redação do Anteprojeto na qual eram previstas competências executivas e legislativas exclusivas da União (arts. 72 e 73), competências comuns executivas com Estados e Municípios (art. 74) e competências comuns legislativas com os Estados (art.75). Esta disposição no Anteprojeto Afonso Arinos influenciou diretamente o Anteprojeto da Comissão de Organização do Estado, na Assembleia Nacional Constituinte de 1987/1988. A redação final, conforme votada em Plenário, trouxe este mesmo sistema de repartição de competências dos arts. 21 ao 24 da Constituição promulgada em 5 de outubro de 1988.

O tema da centralização no federalismo brasileiro, no entanto, merecerá uma análise um pouco mais detida, sendo a ela dedicado integralmente o tópico seguinte. 
FEDERALISMO BRASILEIRO E A CENTRALIZAÇÃO VERTICAL

Para Luiz Fernando Abrucio (1998, p.32), no Brasil, a forma federativa foi adotada com a Constituição de 1891, marcando a ruptura com o modelo unitário vigente no Império.

Todavia, contra esta interpretação clássica acerca do nascimento da federação brasileira, afirma-se que a oficialização da forma federativa, ocorrida em 1891, consistiu antes em um rearranjo do sistema federativo brasileiro do que propriamente em uma ruptura abrupta com um modelo unitário precedente (MARRAFON, 2014, p.103).

De fato, é possível afirmar, conforme a proposta teórica de Livinsgston (1952), que a natureza do federalismo está na sociedade, não na forma constitucional do Estado, que tende a se moldar politicamente para corresponder à federalização social. Neste sentido, expõe Liziero (2017c, p.132):

O federalismo carrega valores tais como a mútua confiança, reciprocidade e heterogeneidade. Por sua vez, o Estado federal é determinado pela Constituição, nominalmente ou não, que estabelece um sistema de distribuição de poderes entre as unidades federativas, central e locais, e de representatividade nas decisões tomadas pelo poder soberano.

Deste modo, conforme este raciocínio, é possível afirmar que havia federalismo no Brasil do Império, ainda que não houvesse a forma federal de Estado. O governo unitário defendido pelos conservadores - contra a federação, defendida pelos liberais, foi o debate parlamentar de destaque no Império (BRESSER-PEREIRA, 2016, p.83). O projeto liberal de Nação ganhou força com a instauração da Regência, após a abdicação de D. Pedro em 1831, que consistiu em um movimento em favor da descentralização, impulsionado pelo Ato Adicional de 1834 (MARRAFON, 2014, p.101).

Com o Ato Adicional, importantes medidas foram adotadas, como a mudança do nome dos Conselhos para Assembleias Legislativas Provinciais, às quais se atribuiu competência legislativa própria e também maior autonomia, na forma de arrecadação de impostos, obras públicas, eleição do vice-presidente da província, controle sobre os municípios e também sobre os cargos do Judiciário (MARRAFON, 2014, p.102). Neste sentido, "o Ato de 1834 criou uma divisão de competências legislativas antes inexistentes, já que era atribuição da Assembléa Geral, conforme o artigo 15, VIII da Constituição de 1824: 'fazer Leis, interpretal-as, suspendelas, e revogal-as'" (LIZIERO, 2017b, p.121).

Apesar de comumente se dizer que, a forma federativa foi instaurada somente em 1891, com a Constituição Republicana, houve outro documento jurídico que instaurou a forma 
federativa de Estado no Brasil preteritamente e que vigorou pouco mais de um ano entre a Proclamação da República e a citada Constituição: O Decreto no 1, de 15 de novembro de 1889. Emitida pelo Governo Provisório, o decreto proclamou como forma de governo da nação brasileira a República Federativa. Em seu art. 2o estabeleceu que as antigas Províncias, reunidas pelo laço da Federação, constituiriam os Estados Unidos do Brasil. Esta determinação do Decreto no1 foi confirmada na Constituição de 1891, em seu art. 1‥

A partir de então, a dinâmica da federação tem sido marcada por "movimentos pendulares", ou seja, momentos de maior autonomia dos Estados e momentos de forte centralização administrativa e fiscal (MARRAFON, 2014, p.104). Esta a razão da assertiva de Bresser-Pereira (2016, p.84), no sentido de que "a construção do Estado brasileiro pode ser pensada como uma luta permanente entre a centralização e o federalismo, como uma sucessão de períodos de centralização aos quais se sucedem períodos de descentralização".

Apesar de se observarem movimentos pendulares, o grau de centralização da Federação brasileira sempre foi alto e historicamente os Estados sempre tiveram poucos mecanismos de veto em relação às decisões tomadas pelo governo federal. Especialmente após a Revolução de 1930, houve uma centralização maior por parte da União, apesar de alguma descentralização durante a égide da Constituição de 1946. Em alguns momentos da história constitucional brasileira é possível observar que, apesar de na forma o Brasil ser uma República Federativa, governantes buscaram solapar o federalismo, fazendo-o apenas nominal durante períodos de autoritarismo. Aqui serão destacados três destes momentos.

O primeiro foi a edição, pelo Governo Provisório de Vargas, do Decreto no 19.398, de 11 de novembro de 1930, que, apesar de sua forma, provocou rupturas na ordem constitucional de 1891. Este decreto, entre outras medias de caráter autoritário, atacou diretamente a autonomia dos Estados, ainda que não abolisse expressamente a forma federal. $\mathrm{O}$ art. 2으 determinou a dissolução de todos os órgãos legislativos do Brasil, inclusive as Assembleias Legislativas dos Estados. A razão principal era já determinada pelo art. 1ํ, com a concentração no Governo Provisório das funções executivas e legislativas. Por sua vez, o art. 11 dava poderes ao Governo Provisório de nomear um interventor para cada Estado e, a seu critério, ser exonerado (art. 11, §3ㅇ). O interventor concentraria em si os Poderes Executivo e Legislativo (art. 11, §1으). Este decreto vigorou, conforme determinava seu art. 1으, até a Constituinte de 1934.

O segundo momento a ser destacado é a decretação (neste termo mesmo) da Constituição de 1937 pelo então Presidente da República, Getúlio Vargas. Além de seu 
conteúdo ser direcionado a fortalecer a figura do Presidente em relação aos outros poderes, criando notável desequilíbrio institucionalizado, houve também grande centralização de poder na União em relação aos Estados. Assim, unia-se a supremacia do Presidente da República com os poderes em demasia da União em um único cargo político. Apesar de manter nominalmente a forma federal de Estado (art. 3ㅇ), esta Constituição trouxe diversos dispositivos que afrontavam a autonomia estatal, requisito observável comumente nas federações. Um deles era o parágrafo único do art. 8o, que determinava que o Estado que por três anos consecutivos não arrecadar receita suficiente para manter seus serviços, seria transformado em Território até sua capacidade financeira ser reestabelecida. Outro era o disposto no art. 178 que dissolveu todos os órgãos do Poder Legislativo, inclusive as Assembleias Legislativas. Enquanto não fossem reestabelecidas, os Governos estaduais (sob os quais o Presidente da República detinha altos poderes de intervenção, conforme ao art. 9ㅇ) exerceriam as funções legislativas (art. 181). Sem contar com o disposto no art. 186, no qual era declarado o estado de emergência em todo o País.

O terceiro momento a ser trazido como federalismo puramente nominal é aquele que se inicia com a Emenda Constitucional no 1 de 1969 que reformulou boa parte da Constituição de 1967. Promulgada pelos Ministros da Marinha de Guerra, do Exército e da Aeronáutica Militar, respectivamente Augusto Rademaker, Aurélio de Lyra Tavares e Marcio de Souza e Mello, esta emenda trouxe diversas limitações às competências dos Estados. O art. 13 os impunha diversas limitações legislativas. Além disso, seu $\S 1$ o dispunha que aos Estados seriam conferidos todos os poderes que, explícita ou implicitamente, não Ihes fossem vedados pela União. Incialmente pode-se pensar que seria um sistema federativo com competências residuais aos Estados e poderes enumerados à União. Todavia, conforme dispunha o art. 8oㅡ, as competências executivas e legislativas da União eram amplíssimas, o que deixava pequena margem para os Estados. Sobre este aspecto, observou Ferreira Filho (1982, p.136) ao escrever sobre o então sistema federativo vigente:

É mantido na Constituição vigente o federalismo, embora muitos se interroguem se isso não ocorre apenas nominalmente. Com efeito, a Constituição de 1967 já era de cunho centralizador, o que foi acentuado pela Emenda de 1969 e pelas alterações posteriores, bem como pela prática desde então instaurada.

Neste mesmo artigo publicado, Ferreira Filho $(1982$, p.139) comenta a situação dos Estados: "conservam os Estados federados o poder de auto-organização. Entretanto, hoje, esse poder está extremamente restringido pelas normas constitucionais federais". E também concluía, a respeito das perspectivas: "o futuro do federalismo no Brasil, à vista do exposto, há 
de ser encarado com pessimismo. Persiste a fraseologia, invoca-se a tradição federativa, mas a realidade muito se aproxima da que se encontra num Estado unitário descentralizado" (FERREIRA FILHO, 1982, p.140).

Apesar do grande anseio pela descentralização na Constituinte de 1987/1988, o que pode ser interpretado como o sentido de federalismo no Poder Constituinte Originário (LIZIERO, 2017a), o modo como a repartição de competências na Constituição foi distribuído, apesar de ter dado alguma autonomia aos Estados, permanece caracterizando o Estado federal brasileiro como centralizador. Além disso, a Constituição criou poucos mecanismos de veto para os Estados se defenderem das decisões tomadas a nível federal que os prejudicassem diretamente e, pelo comportamento principalmente do Senado, mostra-se que os Senadores possuem, ao votar projetos, mais fidelidade ao partido ao qual pertencem do que aos Estados que deveriam representar (ARRETCHE, 2012, p.112-113).

A configuração simétrica da Federação brasileira também contribui para a centralização, uma vez que não há como Estados mais populosos, por exemplo, se eximirem de ser regulamentados por matéria federal votada no Senado com uma coalização de diversos Estados menos populosos. Ainda que o Estado Federal no Brasil tenha mantido a simetria de direito, "a assimetria de direito, tanto no aspecto da representação quanto da autonomia, como caminho de descentralização para o Estado federal brasileiro, é possível de ser concretizada por meio de algumas formas presentes na Constituição" (LIZIERO, 2017a, p.175). A simetria entre os Estados, tanto no âmbito da composição do Senado, quanto na distribuição equânime de competências legislativas e executivas entre os Estados, também são fatores que contribuem para o cenário centralizador da Federação Brasileira.

As disposições federativas da Constituição de 1988, inclusive a concentração de boa parte das competências tributárias na União e grande poder de decisão a respeito da distribuição de receitas, levou inevitavelmente às reformas fiscais dos anos 1990, em conformidade com as pesquisas de Marta Arretche (2012, p.42). Entre as medidas centralizadoras estão: (i) a Emenda no 3/1993, que deu à União o poder de reter créditos de impostos estaduais e municipais naquilo que for necessário para prestar garantia ou contragarantia, além da retenção para pagamento de dívidas; (ii) O Fundo de Estabilidade Fiscal - FSE, que teve por objetivo sanear o Tesouro e para tanto vinculou 20\% das receitas federais com destinação prioritária para a saúde, a educação e benefícios assistenciais e previdenciários, o que diminuiu o repasse os Estados e Municípios; (iii) O PROES, programa que tinha como finalidade buscar a estabilidade financeira dos Estados, bastante endividados. As medidas foram 
direcionadas principalmente aos bancos estaduais públicos, que foram extintos ou privatizados; (iv) A Lei Kandir, que desonerou da cobrança de ICMS diversos produtos e serviços com a finalidade de estimular a importação; (v) A Lei de Responsabilidade Fiscal, que regulamentou e limitou o uso das receitas dos entes federativos, sendo que seus limites levaram à significativa perda de poder decisório dos Estados e Municípios.

É possível, desta forma, notar que a repartição de competências na Constituição de 1988, além de outros dispositivos, criaram facilidades para que propostas legislativas da União afetassem diretamente interesses de Estados e Municípios.

A União detém amplas competências executivas e legislativas, em conformidade com o que a Constituição determina entre seus arts. 21 e 24 . Neste âmbito, a maior parte destas competências são exclusivas e privativas da União (art. 21 e 22). Nas competências comuns e concorrentes (arts. 23 e 24), além de serem numericamente inferiores, a União estabelece regras gerais que devem ser particularizadas pelos Estados.

A Constituição de 1988 também não criou mecanismos de vetos significativos para Estados e Municípios se defenderam contra os desígnios da União (ARRETCHE, 2012, p.77). Assim, como o procedimento de alteração da Constituição é o mesmo, para matérias federativas ou não, a União, no exercício do Poder Legislativo, consegue mobilização suficiente para alterar dispositivos do sistema federativo por meio de emendas constitucionais que podem prejudicar os entes subnacionais, como foi o caso da Emenda Constitucional no 3/1993 e da Emenda Constitucional no 10/1996, que criou o PROES, e da Emenda Constitucional no 14/1996, que criou no art. 34, VII, mais uma hipótese que pode motivar a intervenção federal, z por descumprimento da aplicação do mínimo exigido da receita resultante de impostos estaduais, compreendida a proveniente de transferências, na manutenção e desenvolvimento de ensino. Mais tarde, a Emenda Constitucional no 29/2000, reformou este inciso, acrescentando a ele também ações e serviços públicos de saúde.

A agenda centralizadora nos anos 1990 se dá principalmente com o governo Fernando Henrique Cardoso, conforme resultados da pesquisa realizada por Arretche (2012, p.61), uma vez que foi focada no poder regulatório da União e na imposição de perdas aos Estados, especialmente com a vigência da Lei Kandir. Esta agenda centralizadora também se evidencia com a aprovação pelo Congresso Nacional de diversas normas de caráter uniformizador e centralizador, como a Lei de Concessões, a Lei de Licitações e Contratos, a Lei de Diretrizes e Bases, como também o Estatuto da Cidade. 
Assim, nesse raciocínio, é possível firmar o entendimento no sentido de Marrafon e Liziero (2014, p.36), que observam que após 1988 "o Brasil teria seguido as tendências federativas contemporâneas em direção à centralização, de modo que a União concentrou o planejamento das políticas públicas, restando aos entes subnacionais sua execução".

\section{CONCLUSÃO}

O Brasil, ainda que tenha adotado a forma de Estado federal no primeiro dia da República, sempre foi marcado por diversos momentos de política autoritária da União, na qual as relações federativas com os entes subnacionais foram sensivelmente danificadas. Em 1988, como ansiavam os Constituintes, a forma federal foi mantida e buscou-se a configuração de um Estado federativo mais descentralizado, de modo que pudesse corresponder ao real sentido de federalismo no Brasil.

As Federações norte-americana e alemã são modelos que serviram de inspiração para o desenvolvimento do Estado federal brasileiro, daí a importância de estuda-los de forma comparativa com o federalismo brasileiro. As estruturas norte-americanas foram reproduzidas no Brasil a partir da proclamação da República, inclusive em relação ao sistema de competências e à igualdade de cadeiras no Senado para cada Estado, uma vez que no Império havia diferenças a depender da Província.

O modelo alemão é notado pela busca do federalismo de cooperação, correspondente ao desenvolvimento do constitucionalismo social. Apesar disto, as noções de cooperação no Brasil a partir de 1946 e da Alemanha, com a Lei Fundamental de Bonn de 1949, são notadamente diversas, tendo um sentido no Brasil muito mais uniformizador e com maiores centralizações de competências na União, grande responsável pelo desenvolvimento das regiões mais empobrecidas, ainda que significasse relativa perda de autonomia, especialmente financeira, do Estados.

Apesar da pretensão descentralizadora na Assembleia Nacional Constituinte de 1987/1988, o Estado federal brasileiro continua a centralizar muito poder na União, o que por outro lado impossibilita os Estados de terem participação maior na tomada de decisões. Conforme demonstrado em muitas pesquisas, com destaque para os resultados observados por Marta Arretche, o Brasil em 1988 permaneceu centralizado, o que acabou gerando a crise dos Estados nos anos 1990, levando a diversas reformas de natureza fiscal, que centralizaram ainda mais poder na União.

Revista de Direito da Cidade, vol. 10, no 3. ISSN 2317-7721 pp. 1483-1503 


\section{REFERÊNCIAS}

ABRUCIO, Luiz Fernando. Os Barões da Federação. Os governadores e a redemocratização brasileira. São Paulo: Hucitec -Departamento de Ciência Política, USP, 1988.

ALTHUSIUS, Johannes. Politica. Tradução para o inglês: Frederick S. Carney. Indianapolis: Liberty Fund., 1995.

ARRETCHE, Marta. Democracia, Federalismo e Centralização no Brasil. Rio de Janeiro: Editora FGV/Editora Fiocruz, 2012.

BENOIST, Alain de. The First Federalist. Tradução para o inglês: Julia Kostova. Originalmente publicado na Revista Krisis, n.o 22, março/1999. p 54. Disponível em <https://s3-eu-west1.amazonaws.com/alaindebenoist/pdf/the_first_federalist_althusius.pdf $>$. Acesso em 22 de nov.2017.

BRESSER-PEREIRA, Luiz Carlos. A Construção Política do Brasil: Sociedade, economia e Estado desde a Independência. 3ạ ed. São Paulo: 34, 2016.

BURGESS, Michael. Comparative Federalism: Theory and practice. Routledge: New York, 2006.

ELAZAR, Daniel J. Anàlisi del Federalisme i Altres Textos. Tradução para o catalão de Margarida Trias. Institut d'Estudis Autonòmics: Catalunya, 2011.

Contrasting Unitary and Federal Systems. International Political Science Review. Camberra, v.l 18, n. 3, 237-251, 1997.

Exploring Federalism. Tuscaloosa: University of Alabama, 1987.

FERREIRA FILHO, Manoel Gonçalves. O Estado federal brasileiro. Revista da Faculdade de Direito da Universidade de São Paulo. n.77, pp.131-140, 1982.

GIL, Antonio Arroyo. El Federalismo Alemán en la Encrucijada. Sobre el intento de modernización del orden federativo en la República Federal de Alemania. Madrid: Centro de Estudios Políticos y Constitucionales, 2006.

La Reforma Constitucional del Federalismo Alemán. Estudio Crítico de la 52a Ley de modificación de la Ley Fundamental de Bonn, de 28 de agosto de 2006. Catalunya: Institut d'Estudis Autonòmics, 2009.

HORTA, Raul Machado. Direito Constitucional. 4a ed. Belo Horizonte: Del Rey, 2003.

Organização Constitucional do Federalismo. Revista de Informação Legislativa, a. 22, n.87, pp. 5-22, 1985.

HUEGLIN, Thomas O. Exploring Concepts of Treaty Federalism: A Comparative Perspective. Paper prepared as part of the Research Program of the Royal Commission on Aboriginal Peoples. 1994. p. 65. Disponível em <http://data2.archives.ca/rcap/pdf/rcap-81.pdf.> Acesso em 24 de nov. 2017.

LIVINGSTON, William S. A Note on the Nature of Federalism. Political Science Quarterly, New York, v. 67, n. 1, pp. 81-95, 1952. 
LIZIERO, Leonam Baesso da Silva. Estado federal no Brasil: o federalismo na Constituinte de 1987/1988 e a descentralização pela assimetria. 2017a. Tese (Doutorado em Direito) Faculdade de Direito - Universidade do Estado do Rio de Janeiro, Rio de Janeiro.

O federalismo no Império Brasileiro: da Constituição de 1824 ao Ato Adicional de 1834.

Revista Diorito. v.1, n.1. pp. 112-124, 2017b.

Por um Estado Federal Assimétrico. Insight Inteligência. n. 78, pp. 132-152, 2017c.

LOCKE, John. Segundo Tratado Sobre o Governo. Trad. Anoir Aiex. São Paulo: Abril Cultural, 1979.

LOEWENSTEIN, Karl. Teoría de la Constitución. Tradução para o espanhol de Alfredo Gallego Anabitarte. Barcelona: Ariel, 1979.

LÓPEZ-ARANGUREN, Eduardo. Modelos de Relaciones Entre Poderes. Revista de Estudios Políticos Nueva Época, n.104, Abr/jun, 1999.

MARRAFON, Marco Aurélio. Federalismo Brasileiro: reflexões em torno da dinâmica entre autonomia e centralização. In: CLÈVE, Clèmerson Merlin (Coord.). Direito Constitucional Brasileiro: Organização do Estado e dos Poderes. São Paulo: Revista dos Tribunais, 2014.

MARRAFON, Marco Aurélio; LIZIERO, Leonam Baesso da Silva. Competências constitucionais da União e Supremo Tribunal Federal: fiadores da centralização no federalismo brasileiro. In: FISCHER, Octavio Campos; SANTOS, Scheila Barbosa dos. Federalismo Fiscal e Democracia. Curitiba: Instituto Memória, 2014.

ROVIRA, Enoch Alberti. Federalismo y Cooperación en la República Federal Alemana. Madrid: Centro de Estudios Constitucionales, 1986.

SOUZA, Celina. Federalismo, Desenho Constitucional e Instituições Federativas no Brasil pós1988. Revista de Sociologia e Política, Curitiba, n. 24, 2005.

VALDÉS, Roberto L. Blanco. Los Rostros del Federalismo. Madrid: Alianza, 2012.

WATTS, Ronald L. Sistemas Federales Comparados. Tradução para o espanhol de Esther Seijas Villadangos. Madrid: Marcial Pons, 2006.

Trabalho enviado em 02 de fevereiro de 2018.

Aceito em 25 de março de 2018. 